\title{
THE SCOPE OF NON- IS NON-UNIFORM*
}

\author{
Үоко Үчмото \\ Osaka University
}

1. Sentence 1 can be paraphrased by 3 , but the meaning of 2 is quite different from that of 4 , its corresponding negative:

(1) John is non-Christian.

(2) John became non-Christian.

(3) John is not Christian.

(4) John did not become Christian.

This may appear a matter of course, for the prefix non-, whose semantic function is consistently to express the contradictory of the base, ${ }^{1}$ can be equated with not in case the latter is interpreted as having a scope over the following word and not beyond it. However, if we shift our attention from derivational morphology to the scope of negative elements in the sentences, we will face some problems which cannot be dealt with simply by means of semantic composition through the derivational process.

According to Zimmer (1964: 24), such a sentence as 5a as well as $5 \mathrm{~b}$ can be construed as true under a certain interpretation:

(5) a. Triangles are nonintelligent.

b. Triangles are not intelligent.

c. ??Triangles are intelligent.

We can attribute his observation to the deviation from the categorial presupposition; if we represent the proposition " $a$ is $f$ " as $f(a)$, we can say that $f(a)$ generally presupposes that the referent of $a$ is within the domain of the predicate $f$. The domain of $f$ means a set of the individuals that are meaningfully predicated by the predicate $f^{2}$ Then

* I am very grateful to Taro Kageyama and Seisaku Kawakami who gave me valuable comments, and also to a reviewer of this journal for stylistic improvements. I also wish to thank Taisuke Nishigauchi for his suggestions on the earlier idea which led to this article. The responsibility for the errors is entirely my own.

1 This is a notable difference between non- and un-. The latter is ambiguous as to whether it means contradictory or contrary. It would be disambiguated, however, by the semantic property of the base.

${ }^{2}$ See Allwood, J. et al. (1977: 150). 
$5 c$, for example, is deviant because no triangles are within the domain of intelligent $(x)$. According to Ota (1980:151), it is contradictory and therefore false, and if $5 \mathrm{c}$ is false, then $5 \mathrm{~b}$ is true.

Notice that the truth of $5 \mathrm{~b}$ is attributed to the external negation; the negation of $\mathrm{X}$ interpreted as 6 is called external, which influences various presuppositions accompanying $\mathrm{X}$.

(6) It is not the case that $X$.

Thus it is possible that not in $5 \mathrm{~b}$ denies the membership of "triangles" within the domain of intelligent $(x)$. Then if $5 \mathrm{a}$ is true as Zimmer observes, the problem is how the affixal negation by non- can have the same effect on presuppositional meanings as not and why they lead to different interpretations in certain contexts as in 2 and 4 .

Another interesting problem arises from the observation on the sentences having non-derivative nouns instead of adjectives:

(7) a. ??Triangles are noncommunists.

b. Triangles are not communists.

In this case, the paraphrastic relation does not hold. Though $7 \mathrm{~b}$ can be construed as true on the same basis as $5 \mathrm{~b}, 7 \mathrm{a}$ is false or \#. ${ }^{3}$ This means that non- attached to nouns has no effect on presuppositional meanings; its negative force remains within a word. What makes such a difference between non-derivative nouns and adjectives?

2. According to May (1985), the result of the LF-movement may be NP- and VP-adjunction as well as S-adjunction. However, as he points out, it seems unnatural to consider that the scope domain of VP-adjoined quantifiers is VP; more plausible is the claim that it is not different from that of S-level quantifiers. May reduces this problem to the question of the notion "c-command", based on the following assumptions:

(8) The occurrence of a projection is made up of a set of occurrences of nodes that are featurally nondistinct (that is, identical with respect to syntactic features, bar level, index, etc.).

(May 1985: 56)

(9) To be dominated by X-projection is to be dominated by all the member nodes of that projection.

(ibid.: 57)

Under these assumptions, in a structure like 10, the c-command domain of $\mathrm{B}$ is not the $\alpha$-projection but the $\beta$-projection which includes $\mathrm{A}, \mathrm{C}$ and

${ }^{3}$ Some philosophers admit that a proposition may be neither true nor false, and they give the value \# to such a proposition. 
D.

(10)

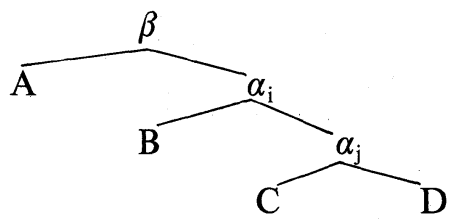

In addition to these, he proposes the Scope Principle:

(11) The Scope Principle (henceforth SP)

Members of $\Sigma$-sequences are free to take on any type of rèlative scope relation, where a class of occurrences of operators $\Psi$ is called a $\Sigma$-sequence iff for any $\mathrm{O}_{i}, \mathrm{O}_{j} \in \Psi$, $\mathrm{O}_{i}$ governs $\mathrm{O}_{j}{ }^{4}$

(May 1985: 34)

May applies this principle to such a sentence as 12 which is ambiguous due to the scope of the quantifiers. The possible LF-representations of 12 are $13 a$ and $13 b$ :

(12) Every student admires some professor.

(13) a. $\left[s^{\prime}\left[s\right.\right.$ every student ${ }_{2}\left[s\right.$ some professor ${ }_{3}\left[s e_{2}\right.$ admires $\left.\left.\left.\left.e_{3}\right]\right]\right]\right]$

b. $\left[\mathrm{s}^{\prime}\left[\mathrm{s}\right.\right.$ some professor ${ }_{3}\left[\mathrm{~s}\right.$ every student ${ }_{2}\left[\mathrm{~s} \mathrm{e}_{2}\right.$ admires $\left.\left.\left.\left.\mathrm{e}_{3}\right]\right]\right]\right]$ In $13 \mathrm{a}$, however, $\mathrm{e}_{2}$ is not properly governed under the descriptive generalization that adjacency is required for coindexed phrases in an $\overline{\mathrm{A}}$ position to govern the subject position. Therefore it is impossible to get the interpretation at LF in which every student has the broader scope, without violating the ECP.

May's proposal then is to make both interpretations available from $13 \mathrm{~b}$, the only LF-representation consistent with the ECP. In 13b, the two quantified phrases satisfy the requisite for the SP, i.e. the relation of government, and hence the relative scope relation is free to be interpreted. The crucial point in May's argument is that at LF, which is a level of syntactic representation, the relative structural positions of the quantified phrases are of importance not to represent the scope interpretation, but only with respect to the structural well-formedness conditions such as the ECP; the LF-representation is merely the input to the semantics, its interpretations and truth-conditions being determined by the rules linking LF and the semantic component such as the SP. This point along with the technical assumptions would be helpful in explicating the effect of non- in the sentences.

\footnotetext{
4 The definition of government is due to Aoun and Sportiche (1983).
} 
3. Now let us assume that besides the LF-movement, the notion and principles mentioned above are applicable to certain morphological constituents including non-. In addition, I propose here the following hypothesis with respect to the scope interpretation of non- on the sentence level:

(14) Non- may be adjoined by Quantifier Raising to AP by which it is dominated.

As I argued in Yumoto (1985) based on Pesetsky (1985), as far as unand non-derivatives are concerned, it seems plausible to establish the morphological LF along with the affix movement that is similar to Quantifier Raising (henceforth QR). Whether my previous proposal is justifiable or not does not affect 14 , however.

We shall now consider how to obtain the possible reading of $5 \mathrm{a}$. If non- is adjoined to AP at LF by 14, the result would be like 15:

(15)

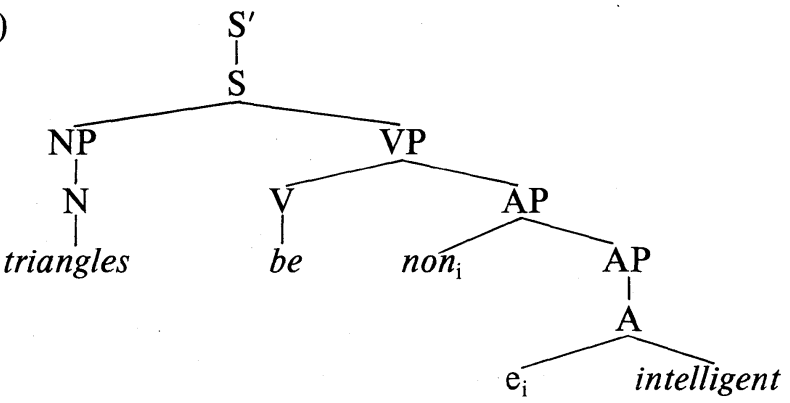

(16)

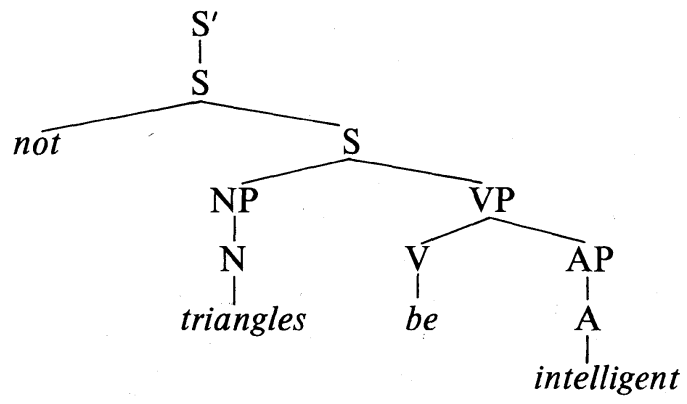

Given May's definition of "dominate" and "c-command", the c-command domain of non- in 15 is VP, whereas that of not in 5 b would be $\mathrm{S}^{\prime}$ as shown in 16. Then the semantic representations of $5 \mathrm{a}$ and $5 \mathrm{~b}$ would look like 17 and 18 respectively:

(17) $[\sim$ Intelligent $]$ (triangles)

(18) $\sim$ [Intelligent (triangles)] 
17 represents the proposition "Triangles are in the domain of $\sim$ intelligent $(x)$ ". Since $\sim$ intelligent $(x)$ and intelligent $(x)$ are in the contradictory relation, 17 can be equated with deviation from the categorial presupposition which we have explained in the first section, though it is subtly different from the true external negation 18 . In 18 , the whole proposition "Triangles are in the domain of intelligent $(x)$ " is negated. Again the categorial presupposition can be cancelled. Thus $5 \mathrm{a}$ and $5 \mathrm{~b}$ are normally interpreted as having the same truth value. However, 15 and 16 are structurally different. Then how can this difference affect the interpretations?

The following pair of sentences will be helpful in answering this question:

(19) a. ??The king of France is nonintelligent.

b. The king of France is not intelligent.

It has been argued that such a sentence as $19 \mathrm{~b}$ is true if it is construed as external negation in which interpretation, the existential presupposition of the subject is cancelled. In contrast, such an interpretation seems impossible for 19a, and hence it is false or \#.

The structural difference at LF shown above would explain this fact. At LF, the subject of the negative sentence is in the scope of not in case of external negation (e.g. 19b, 5b), while the subject predicated by non-derivative adjectives can never be in the scope of non-, even if non-is raised by $\mathrm{QR}$. It indicates that only not can affect the presupposition involved in the definite description in the subject position. Thus the external negation like 18 is vague as to which of the following interpretations is appropriate:

(20) a. The referent of the subject is outside of the domain of intelligent $(x)$.

b. The referent of the subject is not existent at all, and hence its absence in the domain of intelligent $(x)$.

According to the general knowledge of the world, we normally choose the latter interpretation for $19 b$, and the former for $5 b$. As for $5 a$, however, the latter interpretation is impossible for the structural reason in whatever world.

Returning now to the difference between 1 and 2, we will find it plausible that the SP holds for the relation between a predicate and non-, too. Observe the LF-representation of 2 as in 21: 
(21)

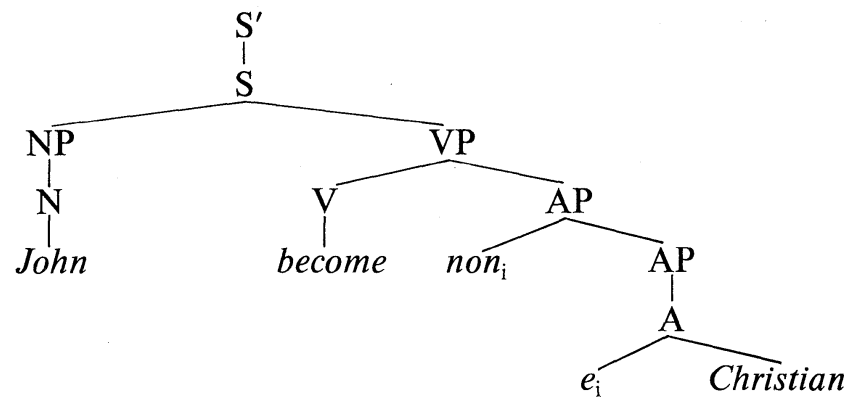

Here, again, the scope of non- is VP, but then is the verb become in the scope of non-? Is the occurrence of a certain change represented by become denied? If so, our analysis would lead to a wrong interpretation.

However, taking the predicate as a kind of operator which might be involved in the SP, we can circumvent such an undesirable result. Since the maximal projection AP intervenes between become and non-, the SP is irrelevant in this case, and so become has the broader scope, which guarantees the appropriate interpretation. On the other hand, in 1 , the negative force extends over the predicate, because the adjective, not the copula $b e$, is interpreted as the predicate.

The final question is, why is a sentence like 7a deviant in contrast with the acceptable 5a? Under our hypothesis 14, non-may be adjoined only to AP but not to NP by QR, although in the derivational process it can be attached to $\mathrm{N}$ as well as $\mathrm{A}$. Therefore 22 would be the sole LFrepresentation of $7 \mathrm{a}$ :

(22)

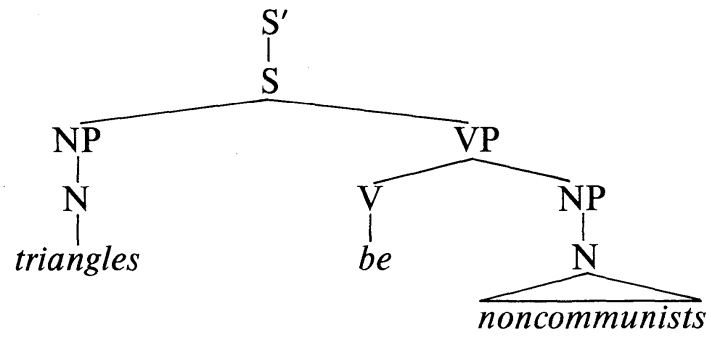

Here non- is not raised above the $\mathrm{X}^{0}$-level, and its effect is at work only within a word. Hence no interpretation of external negation.

4. We have argued that extension of the theory of LF-movement and the SP to the syntax of morphology accounts for the apparent inconsistency of the scope interpretation of non-. Our hypothesis is that nonis one of the affixes that may be involved in the LF-movement on the 
sentence level, and its landing site should be AP-adjunct. The scope interpretation of non- should be derived from the LF representation in accordance with the SP, and its effect on certain kinds of presuppositional meanings are also attributed to its structural relation to predicates or arguments at LF.

\section{REFERENCES}

Allen, Margaret R. 1978. Morphological investigations. Unpublished Ph.D. dissertation, University of Connecticut.

Allwood, Jens, Lars-Gunnar Andersson, and Östen Dahl. 1977. Logic in linguistics. Cambridge: Cambridge University Press.

Aoun, Joseph, and Dominique Sportiche. 1983. On the formal theory of government. The Linguistic Review 2.211-36.

Сномsкy, Noam. 1981. Lectures on government and binding. Dordrecht: Foris. MAY, RoBert. 1985. Logical form. Cambridge, MA: MIT Press.

OtA, AKIRA. 1980. Hitei no imi. Tokyo: Taishukan.

Pesetsky, David. 1985. Morphology and logical form. LI 16.193-246.

Selkirk, Elisabeth. 1982. The syntax of words. Cambridge, MA: MIT Press.

Үчмото, Үоко. 1985. Un-, non-haseigo no LF hyōki ni kansuru ichi kōsatsu. Paper presented at the annual meeting of the ELSJ which was held at Osaka University.

Zimmer, KarL E. 1964. Affixal negation in English and other languages. Supplement to Word. 20. 